\title{
Guía de uso adecuado de modelos animales para el desarrollo de terapias en esclerosis múltiple
}

\author{
Beatriz Moreno, Carmen Espejo, Leyre Mestre, Margarita Suardiaz, Diego Clemente, \\ Fernando de Castro, Óscar Fernández-Fernández, Xavier Montalban, Pablo Villoslada, Carmen Guaza
}

Red Española de Esclerosis Múltiple, REEM (B. Moreno, C. Espejo L. Mestre, M. Suardiaz, D. Clemente, F. de Castro, O. Fernández-Fernández, X. Montalban, P. Villoslada C. Guaza). Institut d'Investigacions Biomèdiques August Pi i Sunyer; Hospital Clínic. Barcelona (B. Moreno, P. Villoslada). Unita de Neuroimmunologia Clínica, UNic; Centre d'Esclerosi Múltiple de Catalunya, CEM-Cat; Vall d'Hebron Institut de Recerca, VHIR Hospital Universitari Vall d'Hebron; Universitat Autònoma de Barcelona; Barcelona (C. Espejo, X. Montalban) Grupo de Neuroinmunología Departamento de Neurobiología Funcional y de Sistemas; Instituto Cajal; CSIC; Madrid (L. Mestre, C. Guaza). Instituto de Neurociencias Clínicas; Hospital Regiona Universitario Carlos Haya; Fundación IMABIS; Málaga (M. Suardiaz,

O. Fernández-Fernández). Grupo de Neurobiología del Desarrollo, GNDe; Hospital Nacional de Parapléjicos; SESCAM; Toledo, España (D. Clemente, F. de Castro)

Correspondencia: Dra. Carmen Guaza. Grupo de Neuroinmunología. Instituto Cajal. CSIC. Avda. Doctor Arce, 37 E-28002 Madrid. E-mail: cgjb@cajal.csic.es

Financiación REEM (RD07/0060/0010; Instituto de Salud Carlos III).

Aceptado tras revisión externa: 14.09.11.

Cómo citar este artículo: Moreno B, Espejo C, Mestre L, Suardiaz M, Clemente D, De Castro $F$, et al. Guía de uso adecuado de modelos animales para el desarrollo de terapias en esclerosis múltiple. Rev Neurol 2012; 54: 114-24.

(c) 2012 Revista de Neurología

Introducción. La búsqueda de terapias efectivas para la esclerosis múltiple (EM) y la definición de ventanas terapéuticas apropiadas, así como el establecimiento de mejores biomarcadores diagnósticos y pronósticos, continúan siendo un reto para investigadores tanto básicos como clínicos. El desarrollo y el método de evaluación de los estudios preclínicos en modelos animales podrían subyacer al hecho de que terapias eficaces en modelos animales fracasen en su aplicación clínica.

Objetivo. Unificar la metodología en la aplicación de los modelos experimentales para la EM mediante la elaboración, por parte de grupos españoles expertos pertenecientes a la Red Española de Esclerosis Múltiple, de una guía de recomendaciones para los estudios preclínicos.

Desarrollo. Se ha realizado una valoración detallada de los modelos experimentales adecuados y su aplicación en función del objetivo perseguido, incorporando estándares y criterios de calidad imprescindibles en un estudio preclínico.

Conclusiones. El éxito traslacional en el avance terapéutico de la EM conlleva la adquisición de compromisos metodológicos en los modelos experimentales, de manera que se optimice la bondad y adecuación del modelo al estudio perseguido. Las recomendaciones establecidas en esta guía podrían ayudar a generar datos preclínicos de utilidad en la práctica clínica.

Palabras clave. Criterios de calidad. Diseño experimental. Esclerosis múltiple. Investigación traslacional. Modelos animales.

\section{Introducción}

La esclerosis múltiple (EM) es la enfermedad crónica inflamatoria más frecuente en el sistema nervioso central y la segunda causa de discapacidad en adultos jóvenes. Aunque se han hecho importantes progresos en su tratamiento terapéutico, los resultados son todavía modestos. Las terapias actuales reducen la frecuencia de los brotes entre un 30-60\% y retrasan la progresión de la enfermedad, así como el riesgo de conversión a la fase secundaria progresiva. En la actualidad se considera que la EM es una enfermedad de naturaleza autoinmune, aunque no hay pruebas de que se deba a una alteración primaria intrínseca del sistema inmune, sino a una respuesta normal a un antígeno inadecuado o a una exposición antigénica inapropiada. Desafortunadamente, tales antígenos no han sido definidos aún. Existe la posibilidad de que la EM pueda ser causada por un virus $u$ otro agente infeccioso, aunque no existen evidencias inequívocas de esta asociación. La validación de un modelo animal es tanto más complicada cuanto menos se conozca la etiología de la enfermedad objeto de estudio, por lo que, en estos casos, se suelen emplear modelos que reproduz- can la mayor parte de los síntomas y, por ello, con gran frecuencia es necesario la utilización de varios modelos animales para el estudio de la patología. En este escenario, el desarrollo de terapias eficaces, la definición de ventanas terapéuticas apropiadas, así como el logro de mejores biomarcadores diagnósticos y, sobre todo, pronósticos en EM sigue siendo un reto para investigadores básicos y clínicos.

Algunas de las razones por las que asistimos a fracasos terapéuticos en la clínica cuando se trata de terapias eficaces en modelos experimentales pueden deberse al propio desarrollo y evaluación de los modelos animales de EM. Es necesario seleccionar el modelo experimental más adecuado en función del objetivo a estudiar y establecer unos criterios de calidad del modelo en cuestión. La investigación de la enfermedad humana se beneficia, sin duda, de los modelos animales; en el caso de la EM, la investigación con modelos animales ha conducido al desarrollo de tres de las cuatro terapias aprobadas para su uso en la enfermedad, lo cual indica la importancia de una buena investigación preclínica y el interés de establecer una guía de recomendaciones a nivel nacional en la aplicación de los modelos experimentales para optimizar los resultados y mejo- 
rar la investigación en el campo. Este artículo revisará los aspectos más críticos en el desarrollo de modelos experimentales y tiene como objetivo general la elaboración de una serie de recomendaciones para unificar la metodología y proponer estándares en la aplicación de los modelos animales en uso por los distintos laboratorios de experimentación animal en EM, con el apoyo de la Red Española de Esclerosis Múltiple. Por ello, en función del objetivo del estudio, se debe tener en cuenta la especie y cepa animal, edad, sexo y otros factores, como la etiología (autoinmune o viral) y el curso clínico de la enfermedad (remitente recurrente, secundaria progresiva o primaria progresiva).

\section{Modelos experimentales de EM}

En este apartado se señalan los modelos animales de EM que, dependiendo de su etiología, se clasifican en autoinmunes y virales, además de su aplicabilidad dependiendo del objetivo de estudio.

\section{Modelos autoinmunes}

Los modelos autoinmunes se engloban bajo el nombre de encefalomielitis autoinmune (alérgica) experimental (EAE). Es una enfermedad experimental inducida, cuya patogenia está mediada por células $T$ específicas frente antígenos de la mielina y comparte similitud clínica e histopatológica con la EM. Es uno de los modelos más antiguos de enfermedad humana. Sus orígenes datan de finales del siglo XIX, de los estudios realizados por Pasteur sobre la vacuna contra el virus de la rabia [1]. La EAE es el modelo experimental más utilizado para el estudio de la EM.

Este modelo puede ser inducido en una gran variedad de especies y utilizarse con diferentes finalidades, pero existe cierta preocupación sobre si el modelo refleja de modo preciso el desarrollo de la enfermedad y, más importante, si puede conducir a resultados y conclusiones equivocadas cuando se utiliza para evaluar posibles terapias. La idea de esta guía es proporcionar un marco adecuado en el cual poder mejorar el valor de este modelo.

La EAE se induce mediante inmunización activa o transferencia de células $T$ específicas contra antígenos de la mielina. Para la inmunización activa se inyecta al animal un homogenizado del sistema nervioso central o bien proteínas o péptidos de la mielina emulsionados en el adyuvante completo de Freund. En algunas especies, como los ratones y los primates, es necesario también la administración de Bordetella pertussis. Aunque se desconoce el me- canismo preciso, se piensa que ésta participa en la permeabilización de la barrera hematoencefálica. De esta forma, se desarrolla una respuesta mediada por células T CD4+ frente al antígeno encefalitogénico utilizado. Para la inmunización por transferencia pasiva, a partir de los ratones inmunizados se obtienen células de ganglios linfáticos o esplenocitos, que son administrados por vía intravenosa a ratones sanos induciendo la EAE. Transcurridos unos 10 días de la inmunización activa o 3-4 días de la transferencia pasiva, aparecen los primeros signos clínicos de EAE, que consisten en una parálisis ascendente que afecta inicialmente la cola y progresa hacia las extremidades anteriores.

Otro grupo adicional de modelos de EAE son los que denominamos modelos espontáneos, ya que no requieren la inducción de la enfermedad para que se desarrollen los signos clínicos. Se utilizan ratones que se han manipulado genéticamente para que expresen un determinado receptor de célula T, específico frente a alguno de los antígenos encefalitogénicos que se utilizan para inducir la EAE mediante inmunización activa. La utilización de estos modelos no está muy extendida entre la comunidad científica, ya que no son disponibles comercialmente. Además, presentan ciertas limitaciones, como la baja incidencia de la enfermedad y los largos períodos hasta que aparecen los signos clínicos [2].

Dependiendo de la especie o cepa y del antígeno encefalitogénico seleccionados, se generan diferentes modelos de EAE que representan las diferentes formas y estadios clínicos de la enfermedad humana (Tabla I) [1,3-5]. En la tabla I también se presenta la posible aplicación de cada modelo al estudio de la patogenia y valoración de agentes terapéuticos. En esta guía se valorarán únicamente los modelos en roedores (debido a su popularidad) y en primates no humanos (debido a su proximidad filogenética con los humanos), aunque existen modelos de EAE desarrollados en otras especies, como conejos, cobayas, etc. $[1,6,7]$.

La EAE monofásica o aguda se caracteriza por la aparición de un único episodio clínico de la enfermedad. El antígeno empleado es la proteína básica de la mielina - myelin basic protein (MBP)- y, aunque la especie animal de excepción para este modelo es la rata (las cepas Lewis y Dark Agouti son muy susceptibles), también puede desarrollarse en ratones $[8,9]$. En la EAE crónica remitente-recurrente se pueden observar dos o más brotes clínicos de la enfermedad. Para este modelo, habitualmente, se trabaja con ratones SJL inmunizados con proteína proteolipídica -proteolipid protein (PLP)-, aunque también se ha descrito en ratas [10]. La EAE crónica 
Tabla I. Modelos de encefalomielitis autoinmune (EAE) experimental en rata, ratón y primates.

\begin{tabular}{|c|c|c|c|c|}
\hline & Cepa & Antígeno & Modelo de EAE & Aplicaciones \\
\hline \multirow{11}{*}{ Rata } & \multirow{4}{*}{ Lewis } & MBP de cobaya & Monofásica & \multirow{4}{*}{$\begin{array}{l}\text { Estudio de: } \\
\text { - Migración de células T autoinmunes } \\
\text { - Control genético de la autoinmunidad } \\
\text { - Validación preclínica de compuestos terapéuticos }\end{array}$} \\
\hline & & $\mathrm{MOG}_{35-55}$ en CFA & Leve & \\
\hline & & $\mathrm{MOG}_{\text {aal-125 }}$ de rata en CFA & Leve & \\
\hline & & $\mathrm{MBP}_{68-82}$ & Monofásica & \\
\hline & \multirow{5}{*}{ Dark Agouti } & $\mathrm{MBP}_{64-80}$ o PLP en CFA o IFA & Monofásica & \multirow{5}{*}{$\begin{array}{l}\text { Estudio de: } \\
\text { - Desmielinización mediada por anticuerpos } \\
\text { - Mimetismo molecular } \\
\text { - Control genético de la autoinmunidad }\end{array}$} \\
\hline & & $\mathrm{MOG}_{\text {aa1-125 }}$ & Crónica o recurrente & \\
\hline & & $\begin{array}{l}\text { Homogenado de } \\
\text { médula espinal de rata DA }\end{array}$ & Remitente recurrente & \\
\hline & & $\begin{array}{l}\text { Mielina bovina } \\
\text { purificada (dosis baja) }\end{array}$ & Monofásica & \\
\hline & & $\begin{array}{l}\text { Mielina bovina } \\
\text { purificada (dosis baja) }\end{array}$ & Remitente recurrente & \\
\hline & \multirow{2}{*}{ Brown Norway } & $\mathrm{MOG}_{\mathrm{aa1}-125}$ & Crónica grave & \multirow{2}{*}{$\begin{array}{l}\text { Estudio de: } \\
\text { - Desmielinización mediada por anticuerpos } \\
\text { - Mimetismo molecular } \\
\text { - Control genético de la autoinmunidad }\end{array}$} \\
\hline & & $\mathrm{MBP}_{63-88}$ & Monofásica & \\
\hline \multirow{10}{*}{ Ratón } & \multirow{2}{*}{$\mathrm{SJL} / \mathrm{J}$} & $\mathrm{PLP}_{139-151}$ & $\begin{array}{l}\text { Remitente } \\
\text { recurrente grave }\end{array}$ & \multirow{2}{*}{$\begin{array}{l}\text { Estudio de: } \\
\text { - Mecanismos que subyacen a los brotes } \\
\text { - Control genético de enfermedades autoinmunes } \\
\text { - Fenómeno de expansión de epítopos } \\
\text { - Desmielinización mediada por anticuerpos } \\
\text { - Influencia de género en la autoinmunidad } \\
\text { Valoración preclínica de compuestos terapéuticos }\end{array}$} \\
\hline & & $\mathrm{MBP}_{84-104}$ & $\begin{array}{l}\text { Remitente } \\
\text { recurrente moderada }\end{array}$ & \\
\hline & \multirow{2}{*}{$\mathrm{C} 57 \mathrm{BL} / 6$} & $\mathrm{MBP}_{84-104}$ & Monofásica crónica & \multirow{2}{*}{$\begin{array}{l}\text { Estudio de: } \\
\quad \text { - Patogénesis mediada por células T CD } 4^{+} \text {Th1/Th17 } \\
\text { - Daño axonal mediado por células T CD8 } 8^{+} \\
\text {Construcción de ratones transgénicos } \\
\text { Validación preclínica de compuestos terapéuticos }\end{array}$} \\
\hline & & $\mathrm{MOG}_{35-55}$ & Crónica moderada & \\
\hline & B10.PL & MBPAC-11 & Monofásica moderada & $\begin{array}{l}\text { Estudio de: } \\
\text { - Células T reguladoras } \\
\text { - Fenómenos de mimetismo molecular y factores } \\
\quad \text { ambientales desencadenantes } \\
\text { - Tolerancia } \\
\text { Validación preclínica de compuestos terapéuticos }\end{array}$ \\
\hline & \multirow{5}{*}{ Biozzi ABH } & $\mathrm{MBP}_{12-26}$ & Leve & \multirow{5}{*}{$\begin{array}{l}\text { Estudio de: } \\
\text { - Mecanismos que subyacen a los brotes } \\
\text { - Desmielinización mediada por anticuerpos } \\
\text { - Daño axonal } \\
\text { Validación preclínica de compuestos terapéuticos }\end{array}$} \\
\hline & & $\mathrm{MAG}_{97-112}$ & Monofásica leve & \\
\hline & & $\mathrm{PLP}_{56-70}$ & Remitente recurrente & \\
\hline & & $\begin{array}{l}\mathrm{MOG}_{8-22} \\
\mathrm{MOG}_{35-55}\end{array}$ & Remitente recurrente & \\
\hline & & $\alpha B$-cristalina ${ }_{1-16}$ & Monofásica leve & \\
\hline \multirow{3}{*}{ Primates } & \multirow{2}{*}{ Rhesus monkey } & $\mathrm{MOG}_{34-56}$ & & \multirow{3}{*}{$\begin{array}{l}\text { Estudio de: } \\
\text { - Neuromielitis óptica } \\
\text { - Proliferación de células T } \\
\text { - Desencadenantes ambientales de autoinmunidac } \\
\text { - Daño axonal } \\
\text { Validación preclínica de compuestos terapéuticos }\end{array}$} \\
\hline & & shOSP & & \\
\hline & $\begin{array}{l}\text { Common } \\
\text { marmoset }\end{array}$ & $\mathrm{MOG}_{14-36}$ & & \\
\hline
\end{tabular}

CFA: adyuvante completo de Freund; IFA: adyuvante incompleto de Freund; MAG: glucoproteína asociada a la mielina; MBP: proteína básica de la mielina; MOG: glucoproteína oligodendrocítica; PLP: proteína proteolipídica. 
sigue un curso progresivo sin brotes y se ha descrito en ratones con dotación genética $\mathrm{H}-2^{\mathrm{b}}$ y ratas inmunizados con glucoproteína oligodendrocítica de la mielina-myelin oligodendrocyte glycoprotein (MOG)$[4,11]$. Este mismo curso clínico se ha descrito para ratones con dotación genética $\mathrm{H}-2^{\mathrm{u}}$ inmunizados con MBP $[12,13]$.

\section{Modelos inducidos por virus}

Estudios de prevalencia y epidemiología de la EM sugieren, además de una susceptibilidad genética, la presencia de un factor ambiental desencadenante, posiblemente de origen viral. La lista de estos patógenos asociados a la EM incluye tanto coronavirus y retrovirus, como algunos miembros de la familia de herpes virus (herpes virus 6 y 7). Además, virus de la familia Paramyxovirus o el virus del moquillo canino han sido aislados en el sistema nervioso central de pacientes con EM. Más recientemente, hay un gran interés en la asociación entre el virus de Epstein-Barr y la EM, no sin cierta controversia al respecto $[14,15]$. A pesar de estas evidencias, no parece que exista una causalidad directa inmediata entre la infección de un único virus y el desarrollo de la EM.

Los modelos de EM que apoyan la etiología viral de la enfermedad implican la inoculación de virus que desarrollan desmielinización en los animales infectados. Entre los virus más utilizados se encuentran virus neurotrópicos, como los coronavirus (virus de la hepatitis murina) o enterovirus (virus de Theiler) en ratón, lentivirus ovino, virus del moquillo canino o el virus Semliki Forest. El modelo viral más extendido es el de la encefalomielitis murina por infección con el virus de Theiler -Theiler's murine encephalomyelitis virus-induced demyelinated disease (TMEV-IDD) - considerado como modelo de EM en su variante primaria progresiva [16]. En la actualidad, Daniel y BeAn son las dos cepas virales de TMEV más empleadas y, aunque su inoculación intracerebral induce una patología desmielinizante crónica tras una primera etapa aguda (polioencefalomielitis), su cinética es diferente [17].

En los modelos virales existe un componente genético, de manera que únicamente algunas cepas de ratones (SJL/J; ABH Biozzi; FVB/NJ) son susceptibles de desarrollar la enfermedad, y un componente ligado al sexo, siendo las hembras las que presentan un mayor grado de susceptibilidad en términos de incidencia y de gravedad de la enfermedad [18]. En los ratones resistentes del haplotipo $\mathrm{H}-2 \mathrm{D}^{\mathrm{b}}$, el virus es eliminado por una fuerte respuesta inmune mediada por células T CD8+, que previene la persis- tencia del virus en la médula espinal y la desmielinización. Una característica importante en este modelo es que la infección con el virus debe realizarse en una ventana de tiempo preferiblemente entre las cuatro a seis semanas de edad. Este hecho estaría en consonancia con la hipótesis de que el origen de la EM podría deberse a una infección viral durante la infancia o adolescencia temprana. Tras la inoculación del virus existe un período de latencia hasta el comienzo de la sintomatología, que puede variar entre los 30-60 días o incluso entre los 90-120 días tras la infección, dependiendo de la cepa del virus, la dosis y la edad del animal. Los signos clínicos de la fase crónica temprana comienzan con espasticidad, debilidad de la cola, fallos de coordinación motora y debilidad de las extremidades, y van avanzando de manera progresiva hasta la parálisis de las extremidades posteriores e incontinencia. Existe, además, un componente autoinmune en la fase crónica tardía, de manera que tiene lugar una respuesta inmune frente a antígenos propios de la mielina debido a la expansión de epítopos [19-21]. Está bien establecida la pauta temporal de desmielinización en la médula espinal y es posible estudiar el daño axonal temprano [22]. Pero, sin duda, la principal cuestión es si el modelo representa de manera adecuada el desarrollo de la enfermedad, teniendo en cuenta la etiología viral y hasta qué punto las terapias aprobadas en EM se muestran eficaces en él. A este respecto, algunas terapias en uso, como el interferón- $\beta$, sí se mostraron eficaces en el modelo viral, mientras que otras, eficaces en la EAE, como linomida, no tuvieron éxito [23].

Las principales variables en este modelo se refieren a la cepa de virus utilizada, la atenuación de la virulencia, la dosis de virus, que puede variar entre $10^{6}$ y $10^{8} \mathrm{PFU}$, la cepa de ratones, el sexo y la fase o estadio de la enfermedad en estudio (fase aguda, fase de transición, fase crónica temprana o fase crónica tardía). La cuantificación de la sintomatología se realiza mediante una escala de puntuación similar a la utilizada en el modelo de EAE, pero también se ha establecido el uso de paradigmas de evaluación de la función motora en un intento de objetivar la evaluación de los déficits motores, como el test de la coordinación motora con el uso del rotarod, la caja de actividad para las medidas de deambulación y, sobre todo, de actividad vertical (muy buen parámetro de medida), o el test de la huella al caminar.

Es importante establecer unas pautas de uso del modelo dependiendo de los objetivos perseguidos, pero, sobre todo, en relación con su uso para estudios preclínicos en la valoración de posibles terapias. En este marco, las consideraciones que se re- 
señarán en el apartado de criterios de calidad en relación con el modelo de EAE servirían igualmente para los modelos virales.

Existen otros modelos de desmielinización inducidos por agentes neurotóxicos químicos o biológicos. Estos modelos pueden compartir determinadas características de la patofisiología de la EAE o EM, y poseen un período de desarrollo de las lesiones muy predecible. Este tipo de modelos son apropiados para estudiar la remielinización cuando el agente químico que provoca la desmielinización es eliminado del sistema, pero no son comparables a los modelos experimentales de EM, por lo que no son objeto de la presente revisión. Los más conocidos utilizan agentes gliotóxicos, como la lisolecitina o la cuprizona $[24,25]$.

\section{Criterios de calidad de los modelos experimentales de EM}

Por término general, toda investigación requiere prever los condicionantes que pudieran surgir a lo largo de la experimentación, intentando minimizar los resultados de artefactos derivados del propio proceso experimental, para lo cual es importante tener en cuenta una serie de criterios de calidad de los modelos experimentales (Tabla II).

\section{Relativos al animal}

El sexo y la edad de los animales pueden afectar el curso de la enfermedad. Las hembras de las cepas de ratón SJL y NZW tienen incidencias de EAE mayores tras la inmunización; en cambio, en las cepas B10/PL y PL/J, los machos desarrollan sintomatología más grave que las hembras [26]. La incidencia de EM en las mujeres es más del doble que la de los hombres, pero éstos tienden a desarrollar casos más graves [27]. La gravedad y la susceptibilidad en el modelo de EAE crecen con la edad [28], y en pacientes de EM, el aumento de la edad también está asociado con la gravedad de la enfermedad [29].

Otra variable a tener en cuenta es el origen del animal. En este sentido, recientemente, se ha descrito que la procedencia de los animales (granjas de distribución) puede afectar a la susceptibilidad y gravedad de los signos clínicos e histopatológicos de EAE para una misma cepa de ratón [30], de lo que se deriva que, cuando se utilizan ratones manipulados genéticamente (knockout o transgénicos), sólo se deben utilizar como control ratones de la misma camada.

\section{Relativos al método}

Como se ha desarrollado en el apartado de modelos experimentales, existen en la actualidad diversos modelos animales que intentan responder, por un lado, a las diversas incógnitas de la etiopatogenia de la EM y, por otro, a la potencialidad de algunos compuestos como agentes terapéuticos de la patología. Por ello el modelo animal empleado variará en función del objetivo previsto.

\section{Tamaño y aleatorización de la muestra}

La asignación de los animales a los diferentes grupos en estudio se debe realizar de manera aleatoria y la puntuación clínica de los animales se debe realizar 'en ciego.' Los estudios en los que no se utilizan estos métodos obtienen mayor número de resultados positivos [31]. A veces el proceso de asignación aleatoria de los animales necesita ser diseñado para ayudar a que los grupos iniciales sean comparables. Por ejemplo, si el peso de los animales varía considerablemente, estratificar a los animales según su peso antes de la selección aleatoria puede resultar muy útil. Aunque obvio, cabe resaltar la importancia de mantener grupos control de cada grupo objeto de estudio, hecho que en muchas ocasiones condiciona el tamaño de la población implicada en el experimento. Debido a la variabilidad intrínseca a la experimentación con animales, se recomienda un mínimo de seis animales por grupo.

\section{Selección del antígeno}

A lo largo de los años se ha descrito una batería de antígenos (fragmentos de proteínas de la mielina o bien proteínas virales) capaces de inducir la sintomatología de la EM. La selección del antígeno va a depender del objetivo del estudio. Por ejemplo, la MBP suele usarse para estudiar la EM aguda, la $\mathrm{MOG}_{35-55}$ modeliza la variante crónica de la EM y la PLP ${ }_{139-151}$ suele emplearse para estudios de EM remitente recurrente. La mínima dosis de antígeno necesaria para el desarrollo fiable de la EAE puede variar en función del origen de síntesis y lote del producto, por lo que es necesario poner el sistema a punto por parte del investigador. Por ejemplo, en ratones de la cepa SJL/J, una sola inmunización con $87 \mu \mathrm{g} /$ ratón de PLP $_{139-151}$ en CFA (adyuvante completo de Freund) con una concentración final de $2 \mathrm{mg} / \mathrm{mL}$ de $M$. tuberculosis es suficiente para inducir una EAE grave en más del $90 \%$ de los casos. Sin embargo, la inducción por el antígeno $\mathrm{MBP}_{84-104}$ requiere dos inmunizaciones con 100 nmol espaciados por una semana. Cuando los ratones de experimentación pertenecen a la cepa C57BL/6, las dosis alcanzan los $200 \mu \mathrm{g}$ para una úni- 
ca inmunización con $\mathrm{MOG}_{35-55}$ [32]. En relación con los adyuvantes necesarios para una correcta inmunización, hay que señalar que, mientras que la cepa $\mathrm{SJL} / \mathrm{J}$ requiere una inyección de $400 \mathrm{ng}$ de toxina pertussis el día de la inmunización y otra dos días después, la concentración se reduce a la mitad en el caso de ratones de la cepa C57BL/6 [32].

En el caso de la experimentación preclínica, hay que tener en cuenta la posibilidad de que los vehículos en que se administran los potenciales agentes terapéuticos puedan interferir en la sintomatología, enmascarando el posible efecto terapéutico del compuesto, por lo que es imprescindible contar siempre con grupos experimentales en los que se administre únicamente el vehículo.

\section{Selección de compuestos, dosis y vías de administración}

Dependiendo del tipo de aproximación (farmacológica, genética, etc.), los resultados de los estudios pueden llevar a diferentes interpretaciones sobre el papel de la molécula que hay que testar en la enfermedad. Los estudios sobre el papel del factor de necrosis tumoral alfa (TNF- $\alpha$ ) en EAE son un buen ejemplo de cómo el uso de diferentes métodos puede llevar a diferentes interpretaciones de los resultados. La administración de TNF- $\alpha$ reduce la duración y la gravedad de la patología en ratones $\mathrm{TNF}^{-/-}$ y $\mathrm{TNF}^{+/+}$con EAE [33], sugiriendo que la administración de TNF- $\alpha$ en pacientes de EM podría limitar la enfermedad. Sin embargo, otro estudio en el que se indujo EAE mediante transferencia pasiva de células T específicas para la MBP, en las que el TNF- $\alpha$ se expresó mediante un vector retroviral, la gravedad de la EAE aumentó [34]. En ensayos clínicos en pacientes con EM, la terapia diseñada para suprimir el TNF- $\alpha$ no funcionó y, en algunos casos, incluso empeoró el desarrollo de la enfermedad [35,36].

También hay que considerar las diferencias en el mecanismo de acción de las moléculas que se van a valorar entre humanos y animales. Las diferencias en tipos de receptores y mecanismos de acción implicados en distintos procesos entre humanos y animales indica la necesidad de modelos que reflejen de forma precisa las respuestas que se producen en humanos. En este sentido, se ha intentado 'humanizar' el sistema inmune para los modelos de EAE [37].

Un método efectivo para identificar la dosis óptima de un compuesto deberá incluir un estudio piloto con un número limitado de animales y un rango de diferentes dosis. Además, los resultados de los estudios piloto pueden servir para determinar el número de animales necesario para conseguir poder estadístico en la siguiente fase del estudio.
Tabla II. Criterios de calidad de un modelo experimental de esclerosis múltiple.

\begin{tabular}{|c|c|}
\hline \multirow{5}{*}{$\begin{array}{l}\text { Relativos } \\
\text { al animal }\end{array}$} & Especie y cepa \\
\hline & Sexo y edad \\
\hline & Origen de procedencia \\
\hline & Aleatorización de los animales \\
\hline & Controles adecuados \\
\hline \multirow{7}{*}{$\begin{array}{l}\text { Relativos } \\
\text { al método }\end{array}$} & Tamaño de la muestra \\
\hline & Selección de compuesto y dosis \\
\hline & Selección de ruta de administración \\
\hline & Selección de vehículo de administración \\
\hline & Identificación de los animales \\
\hline & Seguimiento ciego de los animales \\
\hline & Aplicación de escalas de puntuación sintomatológica \\
\hline \multirow{5}{*}{$\begin{array}{l}\text { Relativos al } \\
\text { seguimiento } \\
\text { y evaluación }\end{array}$} & Registro de signos clínicos de manera individual \\
\hline & Valoración de la sintomatología a la misma hora \\
\hline & Objetividad en la evaluación \\
\hline & Tasa de supervivencia \\
\hline & Método estadístico apropiado \\
\hline
\end{tabular}

Un compuesto efectivo en una dosis razonable y con un perfil toxicológico adecuado puede justificar un futuro ensayo en humanos; sin embargo, el investigador siempre debe tener en cuenta una estrategia de dosis que pueda ser trasladada en el futuro a humanos de forma segura y realista. Existe una guía de la Food and Drug Administration estadounidense que proporciona factores de conversión y una ecuación para poder estimar la dosis equivalente en humanos basada en la dosis utilizada en estudios en diferentes especies animales [38].

El régimen de dosificación de un compuesto debe tener en cuenta el posible mecanismo de acción relativo con la patogenia de la enfermedad. Si se espera que el compuesto en estudio inhiba la inducción de la enfermedad, la dosificación debe comenzar antes, al mismo tiempo o justo después de la inmunización de los animales (2-3 días), cuando las células del sistema inmune ya han comenzado a responder contra el antígeno. Si el mecanismo de acción del compuesto afecta al proceso patológico que lle- 
va directamente a los síntomas clínicos o brotes, la administración puede ser efectuada tras la aparición de los síntomas (de mayor valor preclínico). Hay que tener en cuenta que los pacientes con EM inician tratamiento tras la aparición de los síntomas clínicos, por lo que es conveniente plantear abordajes terapéuticos más que preventivos para tener mayor garantía de que un compuesto testado en el modelo animal funcionará en la EM.

\section{Relativos al seguimiento y evaluación}

\section{Seguimiento y evaluación}

Los factores ambientales influyen en el desarrollo del modelo y, por lo tanto, es importante mantener las condiciones ambientales constantes durante el intervalo del experimento, así como entre experimentos dentro del mismo estudio. La estación del año en la que se realizan los experimentos afecta la susceptibilidad a la enfermedad en las diferentes cepas [28]. La exposición a diferentes tipos de agentes infecciosos hace a los animales resistentes a la inducción de EAE [39], mientras que la enfermedad puede ser reactivada en animales con EAE expuestos a diversas enterotoxinas [40].

El seguimiento del experimento debe realizarse de forma ciega y preferiblemente por dos investigadores que valoren la aparición de la sintomatología de manera independiente, pero manteniendo las mismas condiciones de recogida de datos, como hora del día o lugar. Sus puntuaciones deberán promediarse.

No existe una escala única para valorar el grado de gravedad de la sintomatología. De hecho, parte de la variabilidad de las distintas escalas refleja diferentes patrones de desarrollo de la enfermedad, dependiendo del modelo utilizado. Las escalas varían en puntuaciones que llevan desde máximos de 5 hasta 9 , siendo la más común la que incluye seis intervalos (puntuaciones de 0 hasta 5) [41]. Normalmente, una puntuación de 0 representa un animal de apariencia normal y la puntuación máxima de la escala indica el estado moribundo o la muerte del animal. En la bibliografía se pueden encontrar también trabajos que utilizan una escala de 0 a 4 [42], de 0 a 6 [43], de 0 a 7 [44] o de 0 a 9 [45]. Incluso sistemas de puntuación comparables pueden dar lugar a diferencias en los resultados entre laboratorios, debido a la variabilidad entre animales, el entorno y los procedimientos experimentales. Una escala con intervalos más discretos tiene más potencia para detectar diferencias estadísticas y es una medida más sensitiva en modelos de EAE leves. Las escalas con menos intervalos pueden no ser eficaces en la detección de síntomas muy leves de la enfermedad y, además, no son capaces de distinguir entre diferentes niveles cuando los síntomas clínicos son graves.

La puntuación de los síntomas clínicos está asociada con diversos problemas inherentes. Los síntomas no siempre aparecen de forma coherente. De esta manera, un síntoma asociado con una puntuación elevada puede aparecer asociado a otro síntoma con una puntuación más baja. Otro problema inherente es que los síntomas clínicos individuales que se representan en intervalos separados pueden deberse a una lesión patológica individual, y este tipo de presentación puede sobredimensionar el perfil patológico de la enfermedad. Al contrario, varias lesiones patológicas pequeñas o lesiones en diferentes regiones del sistema nervioso central pueden no dar lugar a síntomas medibles, debido a una poca sensibilidad de la escala o al fracaso al evaluar los síntomas que presenta el animal. Por ello, es deseable incluir estudios de resonancia magnética que permitan visualizar las lesiones del animal y que, a día de hoy, pueden llevarse a cabo con equipos especializados para animales de experimentación.

Además, una posible estrategia para minimizar algunos de los problemas previamente expuestos asociados con la forma clásica de realizar las puntuaciones clínicas en la EAE, a la vez que se mantiene e incluso se mejora la potencia estadística, es utilizar un tipo de escala que evalúa cada síntoma por separado. De esta manera, en lugar de asignar un perfil clínico general a cada animal con una puntuación determinada, los signos clínicos se evalúan y registran de forma individual. Así se evita la suposición de que la aparición de un síntoma da lugar a un estado clínico completo en una escala. Además, este tipo de datos permite realizar estadísticas individuales de cada síntoma clínico o por categorías de síntomas. Esta estrategia, sin embargo, aunque permite obtener datos de forma muy precisa, requiere mucho trabajo, y la manipulación de los animales durante períodos más largos podría alterar el desarrollo normal de la enfermedad.

Hasta la fecha se han utilizado pocos paradigmas de comportamiento para evaluar la EAE. Esta herramienta puede ofrecer una medida cuantitativa más objetiva y precisa de determinados parámetros relacionados con la función motora que los métodos de evaluación clásicos. Los tests de comportamiento se utilizan en modelos específicos de EAE que cursan con lesiones localizadas en la médula espinal [46]. Algunos de los tests que pueden utilizarse son los siguientes:

- Test de locomoción en campo abierto: para evaluar la discapacidad de las extremidades posteriores (actividad vertical). 
- Test de rejilla o test del haz estrecho: para valorar las capacidades motoras.

- Test de rodillos circulantes: para valorar la coordinación motora.

- Test de espasticidad: permite identificar y cuantificar este síntoma clínico que se presenta en la EAE, pero que las escalas clásicas no valoran [47].

Algunos de estos tests se basan en evaluaciones mediante observaciones visuales, lo que requiere la formación específica de los evaluadores, pero, a día de hoy, en la mayor parte de los estudios los resultados se graban y monitorizan.

Los datos clínicos obtenidos de un experimento deben ser analizados de manera adecuada. En los modelos experimentales, normalmente los datos obtenidos de cada grupo se combinan en cada tiempo de estudio y se analizan para obtener información sobre la extensión/progresión de la enfermedad. Se analizan las puntuaciones clínicas medias, máximas y medianas. También es útil evaluar la incidencia, las puntuaciones clínicas en fases concretas de la enfermedad, como el inicio, durante el brote o la fase de recuperación, la puntuación acumulada durante el tiempo de seguimiento, la mortalidad (si la hubiese), etc.

Otro parámetro importante que hay que tener en cuenta tiene relación con la escala temporal de los diferentes eventos, por ejemplo, el tiempo en que se produce la aparición de los primeros síntomas clínicos, el tiempo que transcurre entre brotes clínicos, etc.

La pérdida de peso, medida tanto en gramos como en porcentaje, puede ser un buen indicador de la evolución de la enfermedad. Usando el porcentaje de pérdida de peso de los animales se minimizan las diferencias de peso iniciales entre animales.

\section{Análisis estadístico de los datos}

Los estudios con modelos experimentales normalmente intentan responder a tres tipos de preguntas relacionadas con diferencias entre tratamientos $o$ grupos: preguntas relacionadas con diferencias en la gravedad de la enfermedad, relacionadas con diferencias en el tiempo de aparición de determinados eventos, y relacionadas con tasas o porcentajes de aparición de determinados eventos. Para poder responder a este tipo de preguntas, el investigador necesita tener en consideración las características de las mediciones de las variables, así como la elección del método estadístico que se utiliza.

Análisis de la gravedad de la enfermedad. Se puede estudiar la gravedad de la enfermedad en cada animal (máximo, media o mediana) o la extensión de la enfermedad en cada animal (área bajo la curva, puntuación clínica total o el número de días que el animal pasa con una puntuación específica). La decisión del análisis estadístico apropiado depende de las propiedades de la escala utilizada para la puntuación clínica, la distribución y propiedades de la puntuación resumida, el tamaño de la muestra y los requerimientos del procedimiento estadístico. Si la escala clínica no se puede considerar una escala de intervalo, como ocurre normalmente en los estudios de EAE, o si no se cumplen los supuestos del análisis paramétrico (por ejemplo, cuando se utiliza la mediana o la puntuación máxima como forma estadística resumida), entonces se deberá utilizar el análisis no paramétrico. El test no parámetrico más utilizado es el de Wilcoxon para comparación de dos grupos ( $U$ de Mann-Whitney). Para comparación de más de dos grupos podemos utilizar el test de Kruskal-Wallis. En algunos casos, cuando la escala clínica tiene muchos puntos y las mismas diferencias entre los puntos (escala de intervalo), entonces se puede considerar la posibilidad de utilizar un test paramétrico como el análisis de varianza (ANOVA) de repetición para comparación de los grupos, y un test a posteriori para la comparación entre dos grupos, como el test de la $t$ de Student, de Neuman, Bonferroni o Tukey, dependiendo de las características de la muestra. Se debe tener en consideración que la gran mayoría de las escalas utilizadas en los modelos de EAE no pueden considerarse de intervalo. Para poder utilizar tests paramétricos, las variables en estudio deben tener una distribución normal, y las varianzas, ser homogéneas. Las varianzas homogéneas normalmente se consiguen si los animales se han distribuido de forma aleatoria en los distintos grupos y estos grupos son relativamente parecidos en número.

Las medidas de peso (tanto en gramos como en porcentaje), como variables de intervalo, pueden analizarse con tests paramétricos, siempre asumiendo que el resto de los supuestos para el uso de este tipo de test se cumplen.

Análisis del tiempo de aparición de determinados eventos. Una cuestión que se plantea de forma frecuente es si existen diferencias en el tiempo de aparición de determinados eventos entre los distintos grupos experimentales. Las variables que pueden ser medidas en estas circunstancias son, por ejemplo, el número de días hasta la aparición de los primeros síntomas clínicos, días hasta alcanzar la puntuación clínica máxima, tiempo que trans- 
curre hasta la recuperación de los síntomas clínicos de los animales, tiempo hasta el segundo brote (en los modelos de EAE remitente recurrente), etc. Histopatológicamente también se puede medir el tiempo transcurrido hasta la aparición de los primeros infiltrados inflamatorios, daño axonal o desmielinización en el sistema nervioso central. Los datos referidos al tiempo que transcurre hasta la aparición de un evento requieren el cálculo para cada animal del tiempo (normalmente en días) hasta que el evento ocurre. El mejor tipo de análisis estadístico para este tipo de datos es el 'análisis de supervivencia' o 'análisis de eventos'. Una de las ventajas de este tipo de análisis es que tiene en cuenta los animales que no han sufrido el evento durante el tiempo de estudio o que han sido perdidos antes de comenzar el tiempo de estudio del evento (datos censurados).

Existen diversos métodos y tests estadísticos para determinar diferencias en cuanto a la tasa de supervivencia. Los métodos difieren en el cálculo del intervalo de tiempo utilizado para calcular las estadísticas de supervivencia: puede ser un intervalo específico o tras la aparición del evento en estudio (Kaplan-Meier). Ambos enfoques utilizan métodos no paramétricos en los que no se realizan supuestos sobre la distribución de los datos y pueden usarse con grupos muestrales pequeños.

Otra pregunta interesante que puede ser abordada en estudios con modelos experimentales es la proporción o porcentaje de animales que alcanzan determinado evento o adquieren determinadas características. Concretamente, la proporción de animales dentro de un grupo que sufre determinado evento. La mejor presentación de los datos en este caso se realiza en una tabla de contingencia, y el tipo de análisis que se realiza se denomina análisis de tablas de contingencia.

\section{Conclusiones}

Una de las razones por las que asistimos a fracasos terapéuticos en la clínica cuando se trata de terapias eficaces en modelos experimentales se debe al diseño y evaluación de los datos en los modelos animales de EM. Es necesario seleccionar el modelo experimental más adecuado en función del objetivo de estudio y establecer unos criterios de calidad del modelo en cuestión. Por ello, el éxito traslacional en el avance terapéutico de la EM conlleva la adquisición de compromisos metodológicos por parte de la comunidad científica en la utilización de los modelos experimentales, de manera que se optimice la bondad y adecuación del modelo. Las recomendaciones establecidas en esta guía, como la selección del modelo apropiado, la exigencia de controles adecuados, el tamaño de la muestra, la aleatorización de ésta, la necesidad de ser un estudio ciego, el control del origen de los animales, las escalas de valoración clínica, las pruebas conductuales adicionales o la inclusión de la resonancia magnética, podrían ayudar a generar datos preclínicos de utilidad en la práctica clínica.

\section{Bibliografía}

1. Baxter AG. The origin and application of experimental autoimmune encephalomyelitis. Nat Rev Immunol 2007; 7: 904-12.

2. Krishnamoorthy G, Wekerle H. EAE: an immunologist's magic eye. Eur J Immunol 2009; 39: 2031-5.

3. Gold R, Hartung HP, Toyka KV. Animal models for autoimmune demyelinating disorders of the nervous system. Mol Med Today 2000; 6: 88-91.

4. Mendel I, Kerlero de Rosbo N, Ben-Nun A. A myelin oligodendrocyte glycoprotein peptide induces typical chronic experimental autoimmune encephalomyelitis in $\mathrm{H}-2 \mathrm{~b}$ mice: fine specificity and $\mathrm{T}$ cell receptor $\mathrm{V}$ beta expression of encephalitogenic T cells. Eur J Immunol 1995; 25: 1951-9.

5. Tran EH, Kuziel WA, Owens T. Induction of experimental autoimmune encephalomyelitis in C57BL/6 mice deficient in either the chemokine macrophage inflammatory protein1alpha or its CCR5 receptor. Eur J Immunol 2000; 30: 1410-5.

6. Zamvil SS, Steinman L. The T lymphocyte in experimental allergic encephalomyelitis. Ann Rev Immunol 1990; 8: 579-621.

7. Weller RO. Animal models in demyelinating disease. Curr Opin Neurol Neurosurg 1991; 4: 221-30.

8. Stepaniak JA, Wolf NA, Sun D, Swanborg RH. Interstrain variability of autoimmune encephalomyelitis in rats: multiple encephalitogenic myelin basic protein epitopes for DA rats. J Neuroimmunol 1997; 78: 79-85.

9. Lenz DC, Wolf NA, Swanborg RH. Strain variation in autoimmunity: attempted tolerization of DA rats results in the induction of experimental autoimmune encephalomyelitis. J Immunol 1999; 163: 1763-8.

10. Polman CH, Matthaei I, De Groot CJ, Koetsier JC, Sminia T, Dijkstra CD. Low-dose cyclosporin A induces relapsing remitting experimental allergic encephalomyelitis in the Lewis rat. J Neuroimmunol 1988; 17: 209-16.

11. Weissert R, Wallström E, Storch MK, Stefferl A, Lorentzen J, Lassmann $\mathrm{H}$, et al. MHC haplotype-dependent regulation of MOG-induced EAE in rats. J Clin Invest 1998; 102: 1265-73.

12. Acha-Orbea H, Mitchell DJ, Timmermann L, Wraith DC, Tausch GS, Waldor MK, et al. Limited heterogeneity of T cell receptors from lymphocytes mediating autoimmune encephalomyelitis allows specific immune intervention. Cell 1988; 54: 263-73.

13. Wraith DC, Smilek DE, Mitchell DJ, Steinman L, McDevitt HO. Antigen recognition in autoimmune encephalomyelitis and the potential for peptide-mediated immunotherapy. Cell 1989; 59: 247-55.

14. Sargsyan SA, Shearer AJ, Ritchie AM, Burgoon MP, Anderson $S$, Hemmer B, et al. Absence of Epstein-Barr virus in the brain and CSF of patients with multiple sclerosis. Neurology 2010; 74: 1127-35.

15. Miller SD, Karpus WJ. The immunopathogenesis and regulation of T-cell-mediated demyelinating diseases. Immunol Today 1994; 15: 356-61.

16. Lipton HL. Theiler's virus infection in mice: an unusual biphasic disease process leading to demyelination. Infect Immun 1975; 11: $1147-55$. 
17. Oleszak EL, Chang JR, Friedman H, Katsetos CD, Platsoucas CD. Theiler's virus infection: a model for multiple sclerosis. Clin Microbiol Rev 2004; 17: 174-207.

18. Kappel CA, Melvold RW, Kim BS. Influence of sex on susceptibility in the Theiler's murine encephalomyelitis virus model for multiple sclerosis. J Neuroimmunol 1990; 29: 15-9.

19. Croxford JL, Olson JK, Miller SD. Epitope spreading and molecular mimicry as triggers of autoimmunity in the Theiler's virus-induced demyelinating disease model of multiple sclerosis. Autoimmun Rev 2002; 1: 251-60.

20. Vanderlugt CL, Miller SD. Epitope spreading in immunemediated diseases: implications for immunotherapy. Nat Rev Immunol 2002; 2: 85-95.

21. McMahon EJ, Bailey SL, Castenada CV, Waldner H, Miller $\mathrm{SD}$. Epitope spreading initiates in the CNS in two mouse models of multiple sclerosis. Nat Med 2005; 11: 335-9.

22. Tsunoda I, Fujinami RS. Inside-out versus outside-in models for virus induced demyelination: axonal damage triggering demyelination. Springer Semin Immunopathol 2002; 24: 105-25.

23. Drescher KM, Rivera-Quiñones C, Lucchinetti CF, Rodríguez $M$. Failure of treatment with linomide or oral myelin tolerization to ameliorate demyelination in a viral model of multiple sclerosis. J Neuroimmunol 1998; 88: 111-9.

24. Black JA, Waxman SG, Smith KJ. Remyelination of dorsal column axons by endogenous Schwann cells restores the normal pattern of Nav1.6 and Kv1.2 at nodes of Ranvier. Brain 2006; 129: 1319-29.

25. Matsushima GK, Morell P. The neurotoxicant, cuprizone, as a model to study demyelination and remyelination in the centra nervous system. Brain Pathol 2001; 11: 107-16.

26. Papenfuss TL, Rogers CJ, Gienapp I, Yurrita M, McClain M, Damico N, et al. Sex differences in experimental autoimmune encephalomyelitis in multiple murine strains. J Neuroimmunol 2004; 150: 59-69.

27. Duquette P, Pleines J, Girard M, Charest L, Senecal-Quevillon M Masse C. The increased susceptibility of women to multiple sclerosis. Can J Neurol Sci 1992; 19: 466-71.

28. Teuscher C, Bunn JY, Fillmore PD, Butterfield RJ, Zachary JF, Blankenhorn EP. Gender, age, and season at immunization uniquely influence the genetic control of susceptibility to histopathological lesions and clinical signs of experimental allergic encephalomyelitis: implications for the genetics of multiple sclerosis. Am J Pathol 2004; 165: 1593-602.

29. Ligouri M, Marrosu MG, Pugliatti M, Giuliani F, De Robertis F, Cocco E, et al. Neurological sciences age at onset in multiple sclerosis. Neurol Sci 2000; 21 (Suppl 2): S825-9.

30. DeLuca LE, Pikor NB, O'Leary J, Galicia-Rosas G, Ward LA Defreitas D, et al. Substrain differences reveal novel diseasemodifying gene candidates that alter the clinical course of a rodent model of multiple sclerosis. J Immunol 2010; 184: 3174-85.

31. Bebarta V, Luyten D, Heard K. Emergency medicine animal research: does use of randomization and blinding affect the results? Acad Emerg Med 2003; 10: 684-7.

32. Miller SD, Karpus WJ, Davidson TS. Experimental autoimmune encephalomyelitis in the mouse. Curr Protoc Immunol 2010; chapter 15: unit 15.1.

33. Liu J, Marino MW, Wong G, Grail D, Dunn A, Bettadapura J. TNF is a potent anti-inflammatory cytokine in autoimmunemediated demyelination. Nat Med 1998; 4: 78-83.

34. Dal Canto RA, Shaw MK, Nolan GP, Steinman L, Fathman CG. Local delivery of TNF by retrovirus-transduced T lymphocytes exacerbates experimental autoimmune encephalomyelitis. Clin Immunol 1999; 90: 10-4.

35. Van Oosten BW, Barkhof F, Truyen L, Boringa JB, Bertelsmann FW, Von Blomberg BM, et al. Increased MRI activity and immune activation in two multiple sclerosis patients treated with the monoclonal anti-tumor necrosis factor antibody cA2. Neurology 1996; 47: 1531-4.

36. Wiendl H, Hohlfeld R. Therapeutic approaches in multiple sclerosis: lessons from failed and interrupted treatment trials. BioDrugs 2002; 16: 183-200.

37. Ellmerich S, Mycko M, Takacs K, Waldner H, Wahid FN, Boyton RJ, et al. High incidence of spontaneous disease in an HLA-DR15 and TCR transgenic multiple sclerosis model. J Immunol 2005; 174: 1938-46.

38. U.S. Department of Health and Human Services. Guidance for industry. Estimating the maximum safe starting dose in initial clinical trials for therapeutics in adult healthy volunteers. Pharmacology and toxicology. Rockville, MD: CDER/FDA; 2005.

39. Lehmann D, Ben-NunA. Bacterial agents protect against autoimmune disease. I. Mice pre-exposed to Bordetella pertussis or Mycobacterium tuberculosis are highly refractory to induction of experimental autoimmune encephalomyelitis. J Autoimmun 1992; 5: 675-90.

40. Schiffenbauer J, Johnson HM, Butfiloski EJ, Wegrzyn L, Soos JM. Staphylococcal enterotoxins can reactivate experimental allergic encephalomyelitis. Proc Natl Acad Sci U S A 1993; 90: 8543-6.

41. Fleming KK, Bovaird JA, Mosier MC, Emerson MR, LeVine SM, Marquis JG. Statistical analysis of data from studies on experimental autoimmune encephalomyelitis. J Neuroimmunol 2005; 170: 71-84.

42. Baker D, Butler D, Scallon BJ, O’Neill JK, Turk JL, Feldmann M. Control of established experimental allergic encephalomyelitis by inhibition of tumor necrosis factor (TNF) activity within the central nervous system using monoclonal antibodies and TNF receptor-immunoglobulin fusion proteins. Eur J Immunol 1994; 24: 2040-8.

43. Körner H, Riminton DS, Strickland DH, Lemckert FA, Pollard JD, Sedgwick JD. Critical points of tumor necrosis factor action in central nervous system autoimmune inflammation defined by gene targeting. J Exp Med 1997; 186: 1585-90.

44. Hooper DC, Spitsin S, Kean RB, Champion JM, Dickson GM, Chaudhry I, et al. Uric acid, a natural scavenger of peroxynitrite, in experimental allergic encephalomyelitis and multiple sclerosis. Proc Natl Acad Sci U S A 1998; 95: 675-80.

45. Gold BG, Voda J, Yu X, McKeon G, Bourdette DN. FK506 and a nonimmunosuppressant derivative reduce axonal and myelin damage in experimental autoimmune encephalomyelitis: neuroimmunophilin ligand-mediated neuroprotection in a model of multiple sclerosis. J Neurosci Res 2004; 77: 367-77.

46. Buddeberg BS, Kerschensteiner M, Merkler D, Stadelmann C, Schwab ME. Behavioral testing strategies in a localized animal model of multiple sclerosis. J Neuroimmunol 2004; 153: 158-70.

47. De Lago E, Fernández-Ruiz J, Ortega-Gutiérrez S, Cabranes A, Pryce G, Baker D, et al. UCM707, an inhibitor of the anandamide uptake, behaves as a symptom control agent in models of Huntington's disease and multiple sclerosis, but fails to delay/arrest the progression of different motor-related disorders. Eur Neuropsychopharmacol 2006; 16: 7-18.

\section{Guidelines on the appropriate use of animal models for developing therapies in multiple sclerosis}

Introduction. The advance in the achievement of effective therapies for multiple sclerosis (MS), the definition of appropriate therapeutic windows and to establish better diagnostic and prognostic biomarkers have become a challenging task for both researchers and clinicians. Some pitfalls in clinical trials might be related to lack of adequacy of the preclinical studies in MS experimental animal models. 
Aim. To standardize the methodological protocols of experimental models by developing a set of guidelines for preclinical studies by groups of experts from REEM (Spanish Network for MS).

Development. A guide with recommendations for the application of MS models including a detailed assessment of appropriate experimental models taking into account the objective of the study that has been presented. Standards and quality criteria necessary in a preclinical study have been included.

Conclusions. Standardized animal models of MS are essential to increase the success of the preclinical findings in order to transfer them to the clinical practice.

Key words. Animal models. Experimental design. Multiple sclerosis. Preclinical research. Quality criteria. 